\title{
A translational approach to test anti-inflammatory drugs in a LPS induced acute lung inflammation model in the common marmoset (Callithrix jacchus)
}

\author{
S Seehase ${ }^{1,2}$, S Switalla', V Neuhaus ${ }^{1}$, M Zöller², FJ Kaup², C Schlumbohm³ , E Fuchs ${ }^{3}$, HD Lauenstein ${ }^{1,2}$, K Sewald ${ }^{1}$, \\ JM Hohlfeld ${ }^{1}$, A Braun ${ }^{1}$, S Knauf ${ }^{1,2^{*}}$
}

From 2nd Cross Company Respiratory Symposium

Horsham, UK. 6-7 September 2012

The rising incidence of chronic-obstructive pulmonary diseases is linked to the development of new humanspecific anti-inflammatory therapeutics. In many cases classic rodent models fail to predict reliable data of safety and efficacy, which contributes to a growing demand of models that represent the human situation in more detail e. g., anatomy and immune-response.

Similar to the human setting of segmental lipopolysaccharide (LPS) challenge, we established a LPS induced acute lung-inflammation model in the common marmoset monkey, a small non-human primate. LPS induced inflammation mimics pro-inflammatory aspects of chronic airway diseases associated with neutrophile aggregation.

Healthy animals underwent a first BAL to obtain baseline data. Marmosets were than pre-treated orally with roflumilast $(7 \mu \mathrm{g} / \mathrm{kg} \mathrm{bw})$, a recently approved PDE-4inhibitor, or dexamethasone $(2 \mathrm{mg} / \mathrm{kg} \mathrm{bw})$ as a treatment control on five consecutive days. Sham treated animals served as positive control. Under general anaesthesia $500 \mathrm{ng}$ LPS were instilled into the left half of the lung of each animal, followed by ipsilateral BAL of the LPS challenged lung $18 \mathrm{~h}$ post-provocation. BAL fluid was processed and analysed for cellular and cytokine levels. A whole blood assay performed on day 0 and 5 served as an additional readout.

As expected, LPS induced significant influx of total cells into the airways $(p<0.001)$ mainly through neutrophil aggregation. Pre-treatment with roflumilast resulted in a statistically significant decrease of neutrophil numbers in BAL fluid $(p=0.047)$. Dexamethasone pre-treatment showed a significant reduction in relative cell numbers $(\mathrm{p}=0.047)$, but not in absolute neutrophil numbers $(p=0.076)$. TNF- $\alpha$ levels were significantly increased after LPS provocation and significantly suppressed in roflumilast $(\mathrm{p}=0.048)$ and dexamethasone $(\mathrm{p}=0.036)$ pretreated animals. In the WBA only pre-treatment with dexamethasone resulted in a reduced TNF- $\alpha$ release after ex vivo LPS provocation.

Results from this new translational nonhuman primate model indicate the common marmoset monkey as a promising species to test new anti-inflammatory drugs.

\section{Acknowledgements \\ Funded by: Fraunhofer Society}

\section{Authors' details}

${ }^{1}$ Fraunhofer ITEM, Hannover, Germany. ' $G e r m a n$ Primate Center, LeibnizInstitute for Primate Research, Göttingen, Germany. ${ }^{3}$ Encepharm GmbH, Göttingen, Germany.

Published: 14 August 2013

doi:10.1186/1476-9255-10-S1-P28

Cite this article as: Seehase et al:: A translational approach to test antiinflammatory drugs in a LPS induced acute lung inflammation model in the common marmoset (Callithrix jacchus). Journal of Inflammation 2013 10(Suppl 1):P28.

${ }^{1}$ Fraunhofer ITEM, Hannover, Germany

Full list of author information is available at the end of the article

(c) 2013 Seehase et al; licensee BioMed Central Ltd. This is an Open Access article distributed under the terms of the Creative Commons Attribution License (http://creativecommons.org/licenses/by/2.0), which permits unrestricted use, distribution, and reproduction in any medium, provided the original work is properly cited. 